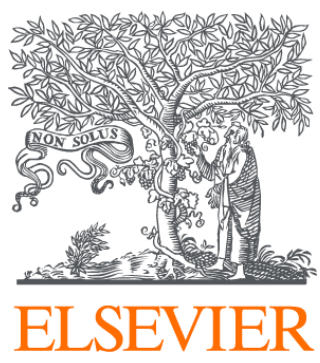

Since January 2020 Elsevier has created a COVID-19 resource centre with free information in English and Mandarin on the novel coronavirus COVID-

19. The COVID-19 resource centre is hosted on Elsevier Connect, the company's public news and information website.

Elsevier hereby grants permission to make all its COVID-19-related research that is available on the COVID-19 resource centre - including this research content - immediately available in PubMed Central and other publicly funded repositories, such as the WHO COVID database with rights for unrestricted research re-use and analyses in any form or by any means with acknowledgement of the original source. These permissions are granted for free by Elsevier for as long as the COVID-19 resource centre remains active. 


\title{
Tracking economic activity in response to the COVID-19 crisis using nighttime lights - The case of Morocco
}

\author{
Mark Roberts \\ Territorial Development Global Solutions Group; Urban, Disaster Risk, Resilience and Land Global Practice, The World Bank, Singapore Office, Singapore
}

\section{A R T I C L E I N F O}

\section{JEL classification:}

C32

C53

O18

R11

Keywords:

Morocco

COVID-19

Nighttime lights

Near real-time monitoring

Economic activity

\begin{abstract}
A B S T R A C T
Over the past decade, nighttime lights have become a widely used proxy for measuring economic activity. This paper examines the potential for high frequency nighttime lights data to provide "near real-time" tracking of the economic impacts of the COVID-19 crisis in Morocco. At the national level, there exists a statistically significant correlation between quarterly movements in Morocco's overall nighttime light intensity and movements in its real GDP. This finding supports the cautious use of lights data to track the economic impacts of the COVID-19 crisis at higher temporal frequencies and at the subnational and city levels, for which GDP data are unavailable. Relative to its pre-COVID-19 trend growth path of lights, Morocco experienced a large drop in the overall intensity of its lights in March 2020 following the country's first COVID-19 case and the introduction of strict lockdown measures, from which it has subsequently struggled to recover. At the subnational and city levels, while all regions and cities examined shared in March's national decline in nighttime light intensity, some suffered much larger declines than others. Since then, the relative effects of the COVID-19 shock across regions and cities appear to have largely persisted. Notwithstanding these findings, however, further research is required to ascertain the exact causes of the observed changes in light intensity and to fully verify that the results are driven by anthropogenic causes.
\end{abstract}

\section{Introduction}

Since it was first identified in Wuhan, China, in December 2019, the COVID-19 virus has swept the globe, resulting in not only a devastating loss of life, ${ }^{1}$ but also widespread economic crisis. In its October 2020 World Economic Outlook, the IMF projected that global real GDP in 2020 would fall by 4.4 percent (IMF, 2020a). This compares to its projection of a 3.4 percent increase made just prior to the global spread of COVID-19 (IMF, 2020b). The loss of incomes has resulted in a major setback in the global fight against extreme poverty, with forecasts indicating a rise of between 119 and 124 million in the number of people living on less than $\$ 1.90$ per day in 2020 due to the pandemic (World Bank, 2021).

Crucial to the formulation of effective policy responses to the crisis is not just up-to-date information on the disease itself, but also "near realtime" data on the associated economic impacts. Such data are important for both the design of economic relief packages and in assessing the possible economic trade-offs associated with lockdowns and other nonpharmaceutical interventions (NPIs) that aim to control the disease's spread. Not only is the availability of near real-time data on economic activity important at the national level, but also at the more local - i.e., subnational regional and city levels - especially as many countries have moved away from national lockdowns to more geographically differentiated strategies of disease containment.

Unfortunately, however, conventional measures of economic activity produced by national statistics offices are ill-suited to providing such (near) real-time monitoring of economic activity. Official data on such activity, even at the national level, are often only available after a long lag and at a relatively low temporal frequency. At best, GDP data tend to be reported at a quarterly frequency at the national level, and an annual frequency at the subnational level. For many developing countries, there are no subnational GDP data at all, and, where they are available, they only tend to be so for very broadly defined geographic regions (Roberts, forthcoming). In light of this, there has been growing research interest in the development of proxy measures of economic activity that can be produced at a high temporal frequency on a (near) real-time basis, including for subnational regions and cities. $^{2}$ Among the alternative indicators that have been investigated are data derived from credit card

E-mail address: mroberts1@worldbank.org.

1 At the time of writing (June 2021), the worldwide death toll from COVID-19 is approaching four million.
2 Some of this interest pre-dates the COVID-19 crisis. The crisis has, however, given an extra impetus to such research. 
transactions and private sector payroll firms (Chetty et al., 2020), Google Trends search data (Woloszko, 2020), and data on outdoor air pollution (Liu et al., 2020; Masaki et al., 2020). In this paper, we investigate the potential of a further unconventional measure of economic activity - outdoor artificial lighting as detected by satellite sensors, commonly referred to as "nighttime lights" - to facilitate (near) real-time tracking of economic activity in response to the COVID-19 crisis, focusing on the specific case of Morocco.

To do this, we use monthly and quarterly measures of nighttime light intensity derived from data collected by the Visible Infrared Imaging Radiometer Suite (VIIRS) sensor onboard the Suomi National PolarOrbiting Partnership (NPP) satellite. We first investigate whether, at the national level, movements in light intensity are correlated with movements in real GDP using quarterly data. ${ }^{3}$ Having established the existence of a statistically significant correlation subject to suitable cleaning of the lights data to remove background noise, we progress to examine the evolution of Morocco's monthly lights following the announcement of the country's first confirmed case of COVID-19 on March 2, 2020 at both the national and subnational (regional and city) levels. In doing so, we focus on measures of nighttime lights that have been adjusted to control for "normal" seasonal variation associated with, for example, possible atmospheric effects and changes in vegetation. ${ }^{4}$ We also examine the evolution of lights following the onset of COVID-19 relative to estimated pre-COVID-19 trends, where these trends define the potential counterfactual evolution of lights in the absence of COVID19.

Our paper builds on a well-established economics literature that uses nighttime lights to proxy economic activity. ${ }^{5}$ This literature dates back to Henderson et al. (2012), who found that the growth of a country's nighttime light intensity provides a good proxy for its GDP growth over the long-term. They also found that fluctuations in light intensity at the national level can track annual fluctuations in economic growth. Since Henderson et al., the use of nighttime lights to proxy economic activity has become commonplace within the economics literature, especially in the urban and spatial economics literatures where analysis is constrained by the lack of official GDP data (see, for example, Bleakley and Lin, 2012; Storeygard, 2016; Jedwab et al., 2021). More generally, a recent review uncovers more than 150 studies in economics that have used nighttime lights (Gibson et al., 2020). However, the use of lights to proxy for economic activity has not been without controversy. Chen and Nordhaus (2011) are more downbeat in their findings than Henderson et al. (2012) on the ability of lights data to reliably proxy economic activity, especially for more agricultural regions. Meanwhile, there is evidence that, while lights can predict longer-run variation in economic activity over space, they perform much more poorly in predicting changes in economic activity over time (Goldblatt et al., 2020).

With only a few exceptions, however, the economics literature that uses nighttime lights measures to proxy levels and changes in economic activity relies on data from Operational Linescan System (OLS) satellite sensors that were part of the now largely defunct US government Defense Meteorological Satellite Program (DMSP). ${ }^{6,7}$ While these data have the advantage of having a relatively long annual time series

\footnotetext{
${ }^{3}$ Quarterly is the highest frequency at which national GDP data are available for Morocco.

4 This still, however, leaves the possibility of distortion of the detection of nighttime lights by atmospheric and other effects that may not follow a regular seasonal pattern. We discuss this possibility further below.

5 This economics literature is pre-dated by several remote sensing studies which investigate the potential of lights to proxy economic activity (see, for example, Sutton et al., 2007).

6 The exceptions include Roberts (2018), Beyer et al. (2021), and Gibson et al. (2021).

7 DMSP still has satellites orbiting and collecting nighttime lights data, but the program will end once the current satellites reach their end of life (World Bank, 2020).
}

spanning 1992-2013, they suffer from several drawbacks that undermine their ability to proxy economic activity (Gibson et al., 2021). Most notable among these drawbacks are those of top coding, "overglow", and the absence of onboard satellite intertemporal calibration of the data.

Top coding refers to the fact that the DMSP-OLS sensors are unable to detect levels of nighttime luminosity above a certain threshold due to sensor saturation. This leads to the cores of many cities, where much economic activity is concentrated, being top coded with the result that increases in their brightness cannot be detected. ${ }^{8}$ Meanwhile, overglow refers to the fact that the light emitted from a given point on the earth is recorded in the DMSP-OLS data as covering an area that extends, often very far, beyond that point. This means that the light, and the economic activity that it potentially measures, is spatially misattributed across locations, which is a particular problem for subnational and city-level analyses. According to Gibson (2020), both top-coding and overglow result in mean-reverting errors in the DMSP-OLS lights data, implying that it understates the true luminosity of brightly lit areas relative to less brightly lit areas. Finally, the absence of onboard intertemporal calibration of the DMSP-OLS data undermines their comparability over time, which may help explain the finding by Goldblatt et al. (2020) that they perform poorly in predicting changes in economic activity.

By contrast, as stated earlier, we make use, in this paper, of lights data from the VIIRS satellite sensor. These are not subject to the topcoding problem, while the overglow problem is also much less severe (Small, 2019). Because the data undergo onboard calibration, they are also more comparable over time (Gibson et al., 2021). As such, the data appear, prima facie, better suited to detecting temporal changes in economic activity than the DMSP-OLS data. Unlike the DMSP-OLS data, which are only available at an annual frequency, the VIIRS data are also publicly available at a monthly frequency with a short time lag, which is crucial for providing potential near real-time monitoring of the economic impacts of the COVID-19 crisis. In seeking to examine the potential of VIIRS lights to track the economic impacts of the crisis, this paper is related to those of Elvidge et al. (2020) and Liu et al. (2020), both of whom demonstrate a dimming and subsequent recovery of VIIRS lights across China associated with the COVID-19 pandemic, and Beyer et al. (2021), who look at the evolution of VIIRS lights for India in response to the pandemic. ${ }^{9}$

From a remote sensing perspective, Morocco is well-suited to the exploration of the potential of nighttime lights to provide high frequency tracking of the economic impacts of the COVID-19 crisis. This is because, by virtue of its latitude, Morocco has very low cloud-coverage, which, for any given month, results in more high-quality observations of lights. The potential study of the economic impacts of COVID-19 in Morocco is also interesting in and of itself given the lack of knowledge about these impacts. At the time of writing, there have been more than 523,000 COVID-19 cases in Morocco and in excess of 9200 deaths. Little, however, is known about the exact evolution of the economic impacts of the crisis on Morocco and how these have played-out across its regions and cities.

The remainder of the paper is structured as follows. Section 2 describes the VIIRS lights data and our procedures for cleaning and processing the data, in addition to the national real GDP data for Morocco. Section 3 describes our analysis of the correlation between changes in nighttime light intensity and real GDP at the national level using

\footnotetext{
${ }^{8}$ In addition to the standard DMSP-OLS lights data, there is a radiancecalibrated version of the data that was derived based on experiments with adjusting the gain settings of the satellite sensors. This version of the data, which is available for seven years between 1996 and 2011, is not subject to top coding.

9 Although not focused on the COVID-19 pandemic, a further related paper is Chodorow-Reich et al. (2020), who study the impacts of India's demonetization on real economic activity across districts using, inter alia, VIIRS data.
} 
quarterly data, which acts as a test of whether lights provide a possible proxy for tracking changes in economic activity, both at a higher temporal frequency and at the subnational (regional and city) levels, in the absence of GDP data. Section 4 presents our analysis of the evolution of nighttime lights at the monthly frequency in response to the COVID-19 crisis at the national, subnational regional, and city levels. Section 5 concludes by discussing caveats and possible future extensions to the analysis.

\section{Data}

\subsection{Nighttime lights data}

As discussed above, the nighttime lights data that we use are derived from observations collected by the VIIRS sensor onboard the Soumi-NPP satellite, which is jointly operated by NASA and the US government's National Oceanic and Atmospheric Administration (NOAA). In particular, we use the monthly composites of VIIRS lights produced by the Earth Observation Group (EOG) at the Colorado School of Mines. ${ }^{10}$ These composites cover virtually the entire globe at a resolution of 15 arc seconds, which is equal to $460 \mathrm{~m}^{2}$ at the equator. ${ }^{11}$ This is much higher than the 30 arc second resolution (approximately $1 \mathrm{~km}^{2}$ at the equator) of the old DMSP-OLS lights data. For each pixel, the composites report luminosity in nanowatts $/ \mathrm{cm}^{2} / \mathrm{sr}$ as an average calculated over all cloud-free nights in a month. We make use of the monthly composites for April 2012-September 2020, where the April 2012 composite is the first that was produced following the launch of the Suomi-NPP satellite in $2011 .^{12}$ As noted in Section 1, because of its latitude, Morocco has very low cloud coverage. As a result, virtually all pixels in the data for Morocco have - after dropping the data for June for each year for reasons that we explain below - at least two nights, and often many more, of cloud free coverage for all months between April 2012 and September $2020 .^{13}$

In creating the monthly composites, EOG filter-out both lightning and lunar illumination prior to averaging. However, unlike the annual composites, which are only currently available for 2015 and 2016, which EOG also produce, they do not filter out lights from aurora, fires, boats, and other ephemeral lights. As such, the data are still subject to, potentially considerable, background noise. To screen out this noise, we undertake further cleaning of the monthly composites by applying various masks to the data. ${ }^{14}$ In particular, we experiment with four different background masks, which we refer to as: (i) the "EOG mask";

\footnotetext{
10 This group was formerly based at NOAA. The group is the same as that which produced the DMSP-OLS annual composite lights data sets on which most research that has used nighttime lights has relied.

11 The composites cover the globe from $75 \mathrm{~N}$ latitude to $65 \mathrm{~S}$.

12 Monthly VIIRS composites are made freely available by EOG with a lag of three months on their website (https://payneinstitute.mines.edu/eog-2/viirs/). We obtained access to the composites through EOG's paid subscription service which provides access with a maximum lag of around two weeks.

13 As an illustration of this, in Section 4.3.2, we analyze the evolution of nighttime lights for the fourteen Moroccan cities that had a 2015 population more than 200,000. For each city, the average share of pixels that have at least two nights of cloud-free coverage, after dropping the data for June for each year, over all months between April 2012-September 2020 exceeds 98.7 percent in all cases. The average share of pixels that have at least one night of cloud-free coverage exceeds 99.5 percent for all cities. This suggests that our results are unlikely to be driven by variations in cloud coverage.

${ }^{14}$ We only apply this additional cleaning for our national and subnational regional analysis of the lights data. For our city-level analysis, low level background noise, which arises largely outside of urban areas, is already de facto masked-out through the definition of the cities.
}

(ii) the "cluster mask"; (iii) the "population mask"; and (iv) the "built-up area" mask. ${ }^{15,16}$ The EOG mask zeroes out lights values for pixels that EOG mask out in the creation of their annual lights products for 2015 and 2016, which, as noted above, have been subjected to further cleaning over and above their monthly composites. ${ }^{17}$ Meanwhile, the cluster mask excludes both outlier lights values and pixels that are identified as belonging to background noise clusters following the procedure of Beyer et al. (2021). The population mask, by contrast, uses the European Commission's GHS-POP gridded population data set to remove lights values that are associated with areas in which no population is estimated to have been present in $2015 .{ }^{18}$ Finally, the built-up area mask removes lights values that are associated with areas in which there was no detected built-up area in 2018. To derive this mask, we use the built-up area layer from the 2018 MODIS land use - land cover product with a $1 \mathrm{~km}$ buffer to account for potential under-detection of built-up area. ${ }^{19}$ It should be noted that none of these masks is perfect all are imperfect substitutes for the full, computationally highly intensive, cleaning procedure that EOG has yet to apply to its series of monthly composites.

As can be seen from Fig. 1, which provides an illustration of levels of light intensity in March 2020 in the vicinity of Morocco's most populous city, Casablanca, and surrounding secondary cities, the cluster mask is the least spatially extensive, in terms of pixels zeroed-out, followed by the EOG mask, population mask and built-up area mask. Unlike the other masks, the built-up area mask zeroes-out all light along the roads that connect the cities in the map. Most notably, along the road corridor that connects the cities of Casablanca, Deroua, Berrechid and Settat. Given that it is a priori unclear which of the masks is best - in terms of allowing changes in lights to proxy changes in economic activity - we treat this as an empirical question. We settle this question by examining the strength of the estimated correlations between the four different cleaned lights data series that result from the application of the masks and GDP (see Section 3 below). ${ }^{20}$

Even after the application of the above described masks, however, distortions in the lights data for Morocco remain for June in each year. This is due to the summer solstice, which results in "stray-light" contamination of the data. Such contamination arises from the SoumiNPP satellite being illuminated by sunlight while observing areas of the Earth's surface where the sun is under the horizon (Elvidge et al., 2017). Given the severity of this contamination for Morocco, we drop the June data for each year in our analysis below. ${ }^{21}$ It is important to

\footnotetext{
15 In their work on China, Liu et al. (2020) instead mask-out pixels with a radiance of less than $5 \mathrm{nW} / \mathrm{cm}^{2} / \mathrm{sr}$, which they associate with vegetation, water, snow, and rural areas.

16 All four masks are constructed using global data sets, implying that they can also easily be constructed for countries other than Morocco.

17 The EOG cleaning procedure is described in Elvidge et al. (2017). Both Beyer et al. (2021) and Gibson et al. (2021) apply similar masks to clean VIIRS monthly composites of background noise for India (Beyer et al.) and China, Indonesia, and South Africa (Gibson et al.).

18 GHS-POP can be downloaded from https://ghsl.jrc.ec.europa.eu/download. php?ds=pop.

19 The MODIS (Moderate Resolution Imaging Spectroradiometer) product is available from https://modis.gsfc.nasa.gov/data/dataprod/mod12.php. MODIS is an instrument aboard NASA's Terra and Aqua satellites.

${ }^{20}$ Given that GHS-POP grids population based on distributing population counts for administrative units across the built-up area within those units, the population mask is also, in effect, a type of built-up area mask. However, the built-up area layer according to which GHS-POP grids population differs from the 2018 MODIS land use - land cover product. The differences in detection of built-up area explain the differences between the two masks.

21 EOG do provide a "stray-light corrected" configuration of their monthly VIIRS composites in addition to the versions of the composites that we use. However, the correction procedure is imperfect and affects the more general quality of the data. The decision to use the non-corrected data and drop June for each year was based on advice from EOG.
} 


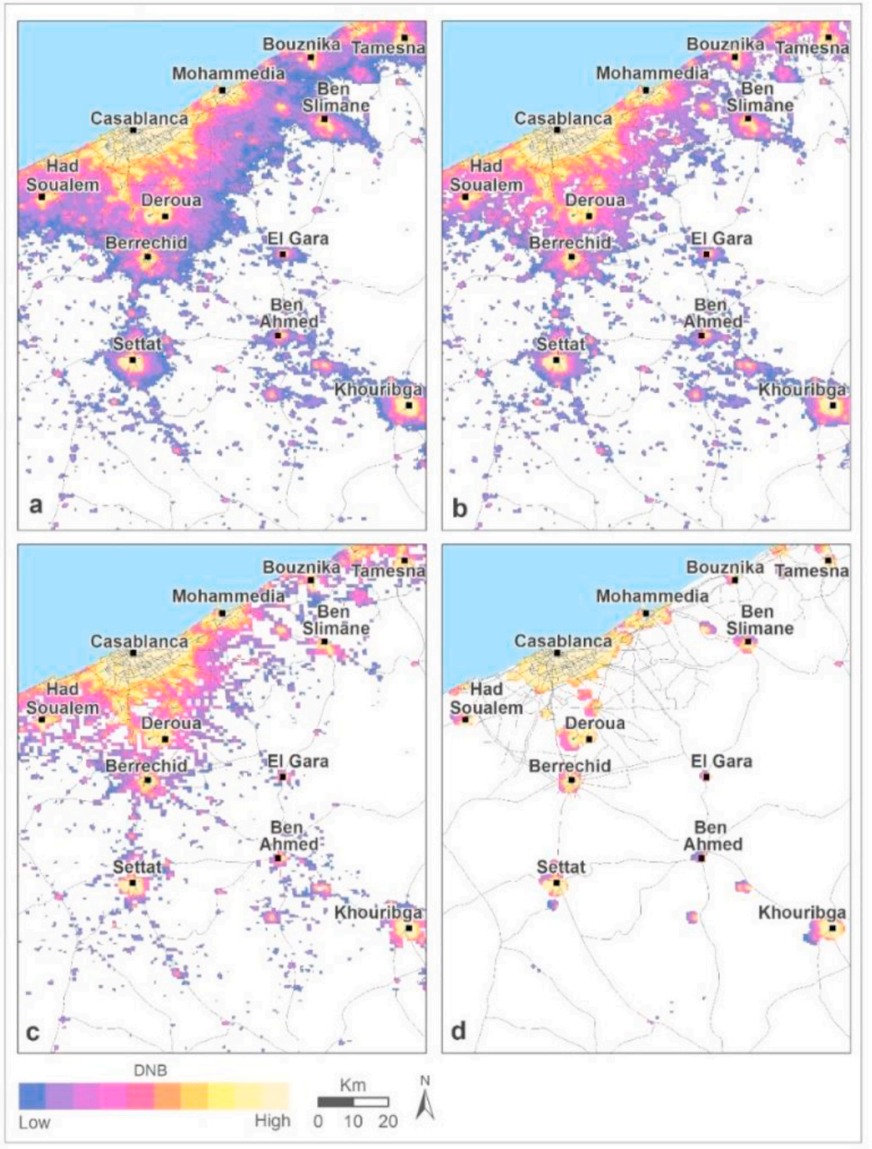

Note: The light gray lines in the maps depict roads based on Open Street Maps data.

Fig. 1. Nighttime light intensity in March 2020 in the vicinity of Casablanca and surrounding secondary cities based on the four different masks: (a) cluster mask; (b) EOG mask; (c) population mask; and (d) built-up area mask.

note that there may also be other sources of distortion in the data associated with, for example, atmospheric effects. To the extent that these follow a predictable seasonal pattern, our analysis below accounts for them. However, this does not rule-out the possibility of distortions arising from atmospheric effects that do not follow such a pattern. If the timing and size of such distortions are, for example, correlated with the onset of the COVID-19 pandemic in Morocco then this will undermine the attribution of changes in lights to causes related to the pandemic.

As our measure of aggregate light intensity, we use the "sum of lights" (SOL), which, for any given area, is derived by summing light intensity values for all pixels in the cleaned data that fall within that area. Hence, we calculate SOL values for all months (bar June for each year) between April 2012 and September 2020 for Morocco overall, its Admin-1 subnational regions, and for all cities which had a 2015 population of at least 200,000. We also calculate quarterly SOL values for Morocco overall by averaging SOL values over the months in each quarter. The quarterly SOL values are used to examine the correlation between changes in lights and changes in real GDP.

\subsection{Real GDP data}

Quarterly real GDP data, which is the highest frequency that is available, covering the period 2012 Q3 - 2020 Q1, come from Morocco's Directorate of Statistics. These are national level data that are measured in chained prices with a base year of 2007 . The data are available only as a seasonally adjusted series, where seasonal adjustment has been performed by the Directorate of Statistics using the US Census Bureau's X12-ARIMA procedure (Findley et al., 1998).

\section{Ability of nighttime lights to track economic activity}

To test whether or not changes in nighttime light intensity can potentially be used to proxy changes in economic activity at a high temporal frequency and/or at spatial scales at which official data on such activity are unavailable, we run several time series regressions to examine the correlation between changes in light intensity and changes in real GDP at the national level for Morocco using quarterly data for the period $2012 \mathrm{Q} 3-2020 \mathrm{Q} 1 .^{22,23}$ These regressions are as follows:

$\ln \left(G D P_{t}\right)=\alpha+\beta t+\gamma Q+\delta \ln \left(S O L_{t}\right)+\varepsilon_{t}$

\footnotetext{
${ }^{22}$ We exclude the Q2 data for each year due to the straylight corruption of the June lights data (see Section 2.1).

${ }^{23}$ Regression models (1)-(3) are static models in the sense that they model a contemporaneous relationship between $\ln$ (SOL) and $\ln$ (GDP). As stated by Wooldridge (2016), in time series analysis, “... a static model is postulated when a change in $\mathrm{z}$ [the independent variable] at time $\mathrm{t}$ is believed to have an immediate effect on y [the dependent variable]." (emphasis added). This implies that, even though the regressions are specified in log levels, the relationship between $\ln (\mathrm{SOL})$ and $\ln (\mathrm{GDP})$ is identified by the changes in the two variables over time.
} 
$\ln \left(G D P_{t}\right)=\alpha+\beta Y+\gamma Q+\delta \ln \left(S O L_{t}\right)+\varepsilon_{t}$

$\ln (G D P)_{D, t}=\alpha+\beta \ln (S O L)_{D, t}+\varepsilon_{t}$

In equation (1), the natural log of Morocco's real GDP in quarter $t$ is regressed on its SOL for the same quarter while controlling for both a linear time trend and quarter effects as captured by the set of quarterly dummies, $Q$. We also estimate equation (1) without the quarterly dummies. In this case, the regression tests whether quarterly changes in SOL are correlated with quarterly deviations of GDP from its growth path. When the quarterly dummies are included, the regression tests whether changes in SOL can predict deviations in GDP around its growth path over and above regular quarterly fluctuations. Meanwhile, in equation (2), the linear time trend from equation (1) is replaced by a full set of year effects, $Y{ }^{24}$ As with equation (1), we estimate (2) both excluding and including the quarter effects, $Q$. Finally, in equation (3), we regress de-trended (ln) GDP on de-trended (ln) SOL where detrending is performed separately for both the $\ln$ (GDP) and $\ln$ (SOL) series. This is done by first separately regressing each of $\ln$ (GDP) and $\ln$ (SOL) on either a linear time trend or a full-set of year effects. The residuals from these separate regressions then act as the de-trended $\mathrm{ln}$ (GDP) and $\ln$ (SOL) time series. ${ }^{25}$ In total, therefore, we estimate six regression specifications - both equations (1) and (2) each with and without the quarter effects, and equation (3) based on de-trending using a linear time trend and year effects. These six specifications are estimated for SOL calculated both on the basis of the "raw" lights data provided by EOG and for each of the four SOL series that have been cleaned using the EOG, cluster, population and built-up area masks. In all cases, regression is by least squares with Newey-West standard errors, assuming a first-order serial correlation process for the error term (Newey and West, 1987). ${ }^{26}$

Table 1 reports the regression results. As can be seen, there is no statistically significant relationship between lights and GDP for any of the six regression specifications when using the "raw" lights data to calculate SOL. The fit of the de-trended regressions in columns [3a] and [3b], as indicated by their $\mathrm{R}^{2}$ values, is furthermore very low. However, once we mask out background noise from the lights data, we do obtain statistically significant relationships for most of the specifications, along with better fits for the de-trended regressions. While this is the case for the results based on all four masks, it is the EOG mask followed by the cluster mask which generates the strongest relationships, judged based both on statistical significance and the fits of the de-trended regressions. If we focus on the column [3b] results then the estimated elasticity of GDP with respect to SOL is 0.295 when using the EOG mask, which is significant at the 1 percent level, with an $\mathrm{R}^{2}$ of 0.37 . This implies that changes in the intensity of Morocco's lights around their trend can "explain" just over one-third of the variation in GDP around its trend. The estimated elasticity of GDP with respect to SOL when using the

\footnotetext{
24 The control for a time trend/year effects helps avoid spurious correlation between nighttime lights and GDP.

25 It will be noted from Table 1 that estimation of equation (3) produces identical point estimates of the coefficient on $\ln \left(S O L_{t}\right)$ as estimation of equation (1) when excluding the quarter effects. The difference lies in the associated standard errors (t-values), which are smaller (larger) when we estimate equation (3).

${ }^{26}$ This is based on the rejection of the hypothesis that the error terms in the regressions are serially uncorrelated using both Durbin's alternative test for serial correlation and the Breusch-Godfrey test for serial correlation. In general, results are very similar when we instead estimate using standard OLS or instead assume a second-order serial correlation process. Note that Newey-West standard errors are also robust to heteroskedasticity.
}

cluster mask is slightly lower at $0.262 .{ }^{27}$ Nevertheless, it remains highly statistically significant. At 0.35 , the $\mathrm{R}^{2}$ is likewise very slightly lower. ${ }^{28}$

Nevertheless, an $\mathrm{R}^{2}$ of $0.35-0.37$ still implies that fluctuations in nighttime light intensity are unable to "explain" almost two-thirds of the quarterly variation in real GDP, meaning that the relationship is rather noisy. This is evident from Fig. 2, which provides a visualization of the column [3b] results based on the EOG and cluster masks from Table 1. Hence, for both masks, the magnitude of the change in lights is much closer to the magnitude of the change in real GDP for some fluctuations than for others. Consistent with this, if we focus on the data for the period 2014 Q1 - 2020 Q1 rather than for 2012 Q3 - 2020 Q1 then the estimated elasticity of GDP with respect to SOL increases to $0.35-0.36$, depending on the mask used. For the most recent fluctuations, visual inspection of Fig. 2 suggests that the elasticity may even be close to unity, especially for results based on the cluster mask.

Despite this, it is also apparent from Fig. 2 that, throughout the sample-period, the timing of changes in nighttime light intensity line-up reasonably with the timing of changes in real GDP, especially for the EOG mask. For the EOG mask, a switch from a below to an above trend level of real GDP or vice versa is matched by a corresponding switch in SOL from below to above trend or vice versa in 10 out of 23 cases (i.e. in 43.5 percent of cases). For the remaining 13 cases, the switch in SOL occurs within plus or minus one quarter of the switch in GDP. Meanwhile, for the cluster mask, a switch in SOL occurs in the same quarter as a switch in real GDP in seven out of 23 cases (30.4 percent) and within one quarter for the remaining 16 cases. This implies that the cleaned lights data are perhaps better used to indicate likely changes in the direction of real economic activity than to provide precise quantitative estimates, based on the overall estimated elasticity, of the change in real GDP for any given fluctuation. Although, even when it comes to detecting the timing of changes in real GDP, significant care still needs to be exercised given that the lights and GDP data do not line-up perfectly. $^{29}$

\section{COVID-19 and the evolution of Morocco's nighttime lights}

\subsection{Methodology for estimating the "impact" of the COVID-19 crisis on lights}

Having established that the lights data can, with reasonable caution, be used to indicate changes in real economic activity, we now turn to examine the evolution of Morocco's lights in response to the COVID-19 crisis. In doing so, we first focus on the monthly evolution at the national level before turning to examine the monthly evolution at the subnational regional and city levels. In all three cases, our methodology involves

\footnotetext{
27 Our estimated elasticity of $0.262-0.295$ is remarkably close to that obtained by Henderson et al. (2012), which they estimate using annual GDP and lights data for a global panel of countries. This is despite Henderson et al.'s analysis being based on the old DMSP-OLS data as opposed to the newer VIIRS data. 28 Table A1 in Annex 1 presents results based on the EOG and cluster masks, from the estimation of equations (1)-(3) for the industry, services, and agricultural sectors. These regressions suggest that fluctuations in light intensity are most highly correlated with fluctuations in industry GDP. This is notably the case in the estimation of equation (2) and of equation (3) when de-trending is based on year effects. Interestingly, fluctuations in light intensity also hold some predictive ability for fluctuations in agricultural GDP when estimating equation (1) and equation (3) when de-trending is based on a linear time trend. ${ }^{29}$ One might suspect the relationship between fluctuations in real GDP and SOL of being asymmetric between economic expansions and contractions. For example, Henderson et al. (2012) hypothesize "the possibility that because some lights growth reflects the installation of new capacity, lights are nondecreasing, so that economic downturns will not be reflected in lights." However, they find no evidence in support of such an asymmetric relationship in their own work, and, from Fig. 2, there likewise seems no evidence to support the existence of an asymmetric relationship in quarterly data for Morocco.
} 
Table 1

Relationship between nighttime lights and GDP, quarterly data.

\begin{tabular}{|c|c|c|c|c|c|c|}
\hline & Time trend & Time trend + quarter effects & Year effects & Year + quarter effects & De-trended (time trend) & De-trended (year effects) \\
\hline & {$[1 \mathrm{a}]$} & {$[1 \mathrm{~b}]$} & {$[2 \mathrm{a}]$} & {$[2 \mathrm{~b}]$} & {$[3 a]$} & {$[3 \mathrm{~b}]$} \\
\hline \multicolumn{7}{|c|}{ "Raw" nighttime lights data } \\
\hline \multirow[t]{2}{*}{$\ln (\mathrm{SOL})$} & 0.025 & 0.020 & 0.083 & 0.006 & 0.025 & 0.083 \\
\hline & $(0.89)$ & $(1.39)$ & $(1.19)$ & $(0.68)$ & $(0.91)$ & $(1.50)$ \\
\hline $\mathrm{R}^{2}$ & 0.95 & 0.99 & 0.93 & 0.99 & 0.03 & 0.11 \\
\hline \multicolumn{7}{|c|}{ EOG mask } \\
\hline \multirow[t]{2}{*}{$\ln (\mathrm{SOL})$} & $0.129 * *$ & $0.088^{* * *}$ & $0.295^{* * *}$ & $0.051^{* *}$ & $0.129^{* *}$ & $0.295^{* * *}$ \\
\hline & $(2.26)$ & $(3.86)$ & $(4.43)$ & $(2.25)$ & $(2.31)$ & $(5.56)$ \\
\hline $\mathrm{R}^{2}$ & 0.96 & 0.99 & 0.95 & 0.99 & 0.13 & 0.37 \\
\hline \multicolumn{7}{|c|}{ Cluster mask } \\
\hline \multirow[t]{2}{*}{$\ln (\mathrm{SOL})$} & $0.100 * *$ & $0.06^{* * *}$ & $0.262^{* * *}$ & 0.035 & $0.100^{* *}$ & $0.262^{* * *}$ \\
\hline & $(2.11)$ & $(3.11)$ & $(4.23)$ & $(1.54)$ & $(2.16)$ & $(5.30)$ \\
\hline $\mathrm{R}^{2}$ & 0.96 & 0.99 & 0.95 & 0.99 & 0.11 & 0.35 \\
\hline \multicolumn{7}{|c|}{ Population mask } \\
\hline \multirow[t]{2}{*}{$\ln (\mathrm{SOL})$} & $0.109^{*}$ & $0.089 * * *$ & $0.250^{* * *}$ & $0.051^{* *}$ & $0.109^{*}$ & $0.250 * * *$ \\
\hline & $(1.91)$ & $(3.96)$ & $(3.26)$ & $(2.52)$ & (1.96) & $(4.09)$ \\
\hline $\mathrm{R}^{2}$ & 0.96 & 0.99 & 0.94 & 0.99 & 0.10 & 0.29 \\
\hline \multicolumn{7}{|c|}{ Built-up area mask } \\
\hline \multirow[t]{2}{*}{$\ln (\mathrm{SOL})$} & 0.082 & $0.087^{* * *}$ & 0.197 & $0.052^{* * *}$ & 0.082 & $0.197^{*}$ \\
\hline & $(1.17)$ & $(3.65)$ & $(1.55)$ & $(3.81)$ & $(1.20)$ & $(1.94)$ \\
\hline $\mathrm{R}^{2}$ & 0.95 & 0.99 & 0.93 & 0.99 & 0.06 & 0.18 \\
\hline
\end{tabular}

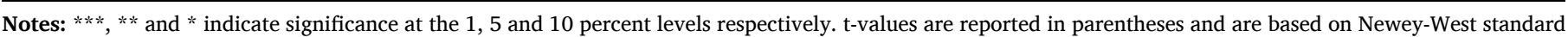
errors, assuming a first-order serial correlation process. Estimated constant terms in the regressions not reported.

a

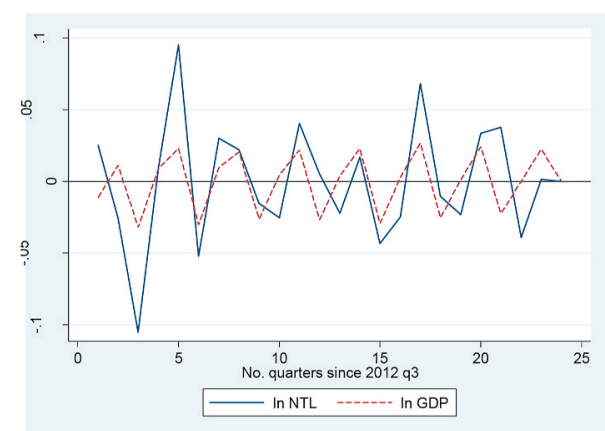

b

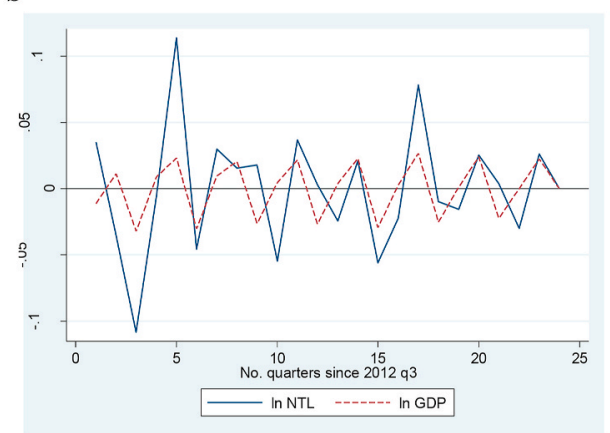

Notes: Based on column [3b] regression results in Table 1 for the sample-period 2012 Q3 - 2020 Q1. Estimation results exclude Q2 data due to corruption of the June nighttime lights data associated with the straylight phenomenon.

Fig. 2. a. Relationship between nighttime lights and GDP, EOG mask. Fig. 2b. Relationship between nighttime lights and GDP, cluster mask.

estimating a multivariate regression that models the evolution of SOL as following an exponential time trend while controlling for systematic differences in light intensity between months that are allowed to differ between the pre- and post-COVID-19 onset periods. From this model, SOL values adjusted for both seasonal effects - in particular, adjusted for systematic monthly variations in the lights data that may be due, for example, to seasonal atmospheric effects and changes in vegetation that are unrelated to economic activity - and the pre-crisis trend are derived, and changes in these values calculated.

More formally, using monthly SOL data for the period April 2012-September 2020 (excluding June data for each year), we estimate the following regression:

$\ln \left(\right.$ SOL $\left._{i, m}\right)=\alpha+\beta m+\gamma$ Month $+\delta($ COVID.Month $)+\varepsilon_{i, m}$

where $S O L_{i, m}$ is a geographic area $i$ 's SOL in month $m, m$ is a time-trend variable, Month are a full set of monthly dummies that help control for seasonal effects, including those associated with possible seasonal atmospheric and other sensor related effects, and COVID is a dummy variable which equals one if a month falls in the post-COVID-19 onset period and zero otherwise. ${ }^{30}$ Given that Morocco's first case of COVID19 was announced on March 2, 2020, we define the post-COVID-19 onset period as consisting of all months from March 2020 onwards. For pre-COVID-19 months, the estimated residuals from this regression, $\widehat{\varepsilon}_{i, m}$, give the seasonally adjusted SOL values relative to the pre-COVID19SOL trend growth path, the estimated slope of which is itself given by $\widehat{\beta}$. Meanwhile, $\widehat{\delta}$ provides estimates of seasonally adjusted SOL values relative to the pre-crisis trend for post-COVID-19 onset months. As with the regressions in Section 3, we estimate equation (4) using least squares with Newey-West standard errors to control for both first-order serial correlation and heteroskedasticity. ${ }^{31}$

\footnotetext{
30 The monthly dummies also help to control for any seasonal variation in cloud coverage, although, as discussed in Section 2.1, cloud-free coverage is high in Morocco, suggesting that this is not a major concern when analyzing lights data for the country.

${ }^{31}$ As with the regressions in Section 3, the use of Newey-West standard errors is justified by the rejection of the hypothesis that the error terms are serially uncorrelated using both Durbin's alternative test for serial correlation and the Breusch-Godfrey test for serial correlation.
} 
A corollary of our approach to examining the evolution of lights following the onset of COVID-19 is that we effectively use the preCOVID-19 trend growth path of an area's lights - be the area Morocco overall or one of its subnational regions or cities - as defining the counterfactual relative to which changes in seasonally-adjusted light intensity are measured. A conceptual illustration of this is provided by Fig. 3. In this figure, $\widehat{\varepsilon}_{F e b}$. is the (hypothetical) residual from estimating equation (4) for February 2020 - the last pre-COVID-19 onset month and corresponds to the (ln) percentage points by which area $i$ 's seasonally adjusted SOL deviated from its pre-COVID-19 growth trend in that month. Meanwhile, $\widehat{\delta}_{\text {March }}$ corresponds to the estimated coefficient on the interaction dummy variable (COVID.Month) for March 2020. This is an estimate of the (ln) percentage points by which area $i$ 's seasonally adjusted SOL deviated from the pre-COVID-19 growth trend in the month in which Morocco's first COVID-19 case was announced. Given this, $\widehat{\delta}_{\text {March }}-\widehat{\varepsilon}_{F e b}$. then provides a measure of the "impact" of COVID-19 on area $i$ 's (seasonally adjusted) light intensity, which is equal to the (ln) percentage point change in SOL between the two months relative to the estimated pre-COVID-19 trend growth path of nighttime light intensity.

In addition to presenting estimates of changes in seasonally adjusted SOL relative to the pre-COVID-19 estimated trend growth path, we also present estimates of year-on-year (y-o-y) changes in seasonally adjusted SOL relative to this same growth path. For March 2020, such an estimate corresponds to $\widehat{\delta}_{\text {March }}-\widehat{\varepsilon}_{\text {March,2019 }}$ where $\widehat{\varepsilon}_{\text {March,2019 }}$ is the residual for March 2019 from estimating equation (4).

The application of the above methodology to derive estimates of "impact" for any given geographic area is subject to at least one important caveat. This is that, ideally, we would like to be able to compare the evolution of lights before and after the onset of COVID-19 with the evolution in a set of comparison locations that did not experience COVID-19. This would then facilitate the application of a difference-in-differences estimator with the evolution of lights in the comparison locations defining the counterfactual against which the impact of COVID-19 is estimated. Given a suitable set of comparison locations, the application of such an estimator would help to control for omitted variables that are common to both the COVID-19 affected and comparison locations, but which may be correlated with both the intensity of nighttime lights and COVID-19. This could potentially include

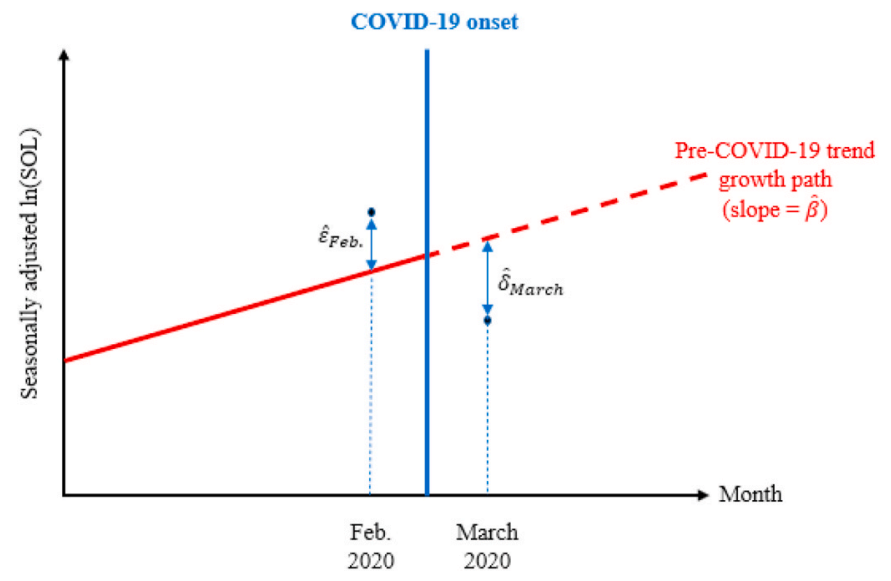

Fig. 3. Conceptual illustration of estimation of effects of COVID-19 on nighttime light intensity.

non-seasonal and unaccounted for atmospheric effects that may lead to distorted nighttime lights measurements. In the absence of such a research design, and, in particular, given our simpler time series design, we cannot completely rule-out the possibility of a large atmospheric "shock" that could have coincided with the onset of the COVID-19 crisis to cause a decline in measured nighttime light intensity in the absence of any "true" on-the-ground change in luminosity. Unfortunately, however, the global nature of the COVID-19 pandemic makes such a research design unfeasible. This means that caution must be exercised in interpreting the estimates of "impact" that we present as causal.

\subsection{National-level results}

The monthly national level results based on the EOG mask which generates the strongest relationship between lights and real GDP in quarterly data (see Section 3) are presented in Table 2 and Fig. $4 .{ }^{32} \mathrm{We}$ highlight three key findings. The first is that, following the detection of the first COVID-19 case and the imposition of strict non-pharmaceutical interventions (NPIs) to control the disease's spread, Morocco witnessed a sharp fall in the intensity of its nighttime lights. Fig. 5 shows the sharp increase in the numbers of confirmed COVID-19 cases and deaths that occurred in Morocco in March 2020 following the detection of the first case, while Fig. 6 shows the sharp increase in the stringency of Morocco's NPIs, as captured by the NPI stringency index constructed by Hale et al. (2020), that was implemented in reaction to this. Accompanying this, Morocco witnessed a steep month-on-month decline of 10.9 percentage points in its overall light intensity (i.e. seasonally adjusted SOL) relative to the pre-crisis trend (Table 2; Fig. 4). ${ }^{33}$ As a result, whereas in February 2020, prior to the first case, the intensity of Morocco's lights had been 3.0 percentage points above its pre-COVID-19 trend, by March, the intensity was 7.9 percentage points below its pre-COVID-19 trend (Table 2; Fig. 4(a)). This month-on-month decline in lights was the largest that Morocco had experienced since December 2013. ${ }^{34}$ An even larger decline in light intensity, relative to the pre-crisis trend, is evident on a year-on-year basis - between March 2019 and March 2020, seasonally adjusted SOL fell by 13.4 percentage points relative to this trend. This is the fifth largest year-on-year decline in seasonally adjusted SOL during the entire time-series of monthly lights.

The second key finding is that Morocco's lights showed some signs of recovery in May 2020 as COVID-19 cases and deaths both leveled-off. Hence, following March's large drop, Morocco experienced a further, much smaller, drop in its overall (seasonally adjusted) light intensity in April 2020 of 3 percentage points, relative to the pre-COVID-19 trend (Table 2). This left Morocco's lights 13.9 percentage points dimmer in April 2020 than they were in February 2020, the final pre-crisis month (Fig. 4). May, however, then saw a partial recovery in the intensity of Morocco's seasonally adjusted lights as the numbers of confirmed COVID-19 cases and deaths stabilized (Fig. 5). Relative to the pre-crisis trend, seasonally adjusted light intensity increased by 6.3 percentage points between April and May 2020 (Table 2). On a year-on-year basis, however, May's change in nighttime light intensity remained negative.

In our final key finding, however, the partial May recovery was shortlived, and, by September 2020, Morocco's lights were as dim as they were in March following the initial impact of the COVID-19 shock. Hence, although we lack useable June lights data due to the stray-light problem, Fig. 4 shows that, by July, the May uptick in seasonally adjusted light intensity had been more than wiped-out. Relative to the pre-crisis trend, light intensity had thus reverted to just below its April

\footnotetext{
32 Results based on the application of the cluster, population, and built-up area masks, which are similar to the results based on the EOG mask, are available on request. The full results from the estimation of equation (4) based on the EOG mask can be found in Table A2, Annex 2.

33 Assuming an elasticity of 0.30 , this corresponds to a fall in real GDP of 3.3 percentage points, although, as discussed in Section 3 , any precise estimate of the change in real GDP derived from the lights data needs to be treated with caution.

${ }^{34}$ The fall was also the fourth largest since data records began. The three largest month-on-month declines in seasonally adjusted light intensity relative to the pre-COVID-19 trend were in December 2013 (-14.70 percentage points), March 2013 (-14.28 percentage points), and November 2012 (-14.07 percentage points). These declines all took place during the Arab Spring period.
} 
Table 2

Nighttime lights statistics.

\begin{tabular}{|c|c|c|c|c|c|c|}
\hline \multicolumn{7}{|c|}{ Difference from trend (\%) } \\
\hline Feb. 2020 & Mar. 2020 & $\begin{array}{l}\text { Apr. } \\
2020\end{array}$ & May 2020 & $\begin{array}{l}\text { Jul. } \\
2020\end{array}$ & $\begin{array}{l}\text { Aug. } \\
2020\end{array}$ & $\begin{array}{l}\text { Sep. } \\
2020\end{array}$ \\
\hline 3.00 & $-7.88^{* *}$ & $-10.92^{* * *}$ & $-4.58 * *$ & $-11.55^{* * *}$ & $-7.03^{* *}$ & $-7.34 * * *$ \\
\hline \multicolumn{7}{|c|}{ Change relative to trend (percentage points) } \\
\hline & $\begin{array}{l}\text { Feb. } \rightarrow \text { Mar. } \\
-10.88\end{array}$ & $\begin{array}{l}\text { Mar. } \rightarrow \text { Apr. } \\
-3.03\end{array}$ & $\begin{array}{l}\text { Apr. } \rightarrow \text { May } \\
6.34\end{array}$ & $\begin{array}{l}\text { May } \rightarrow \text { Jul. } \\
-6.97\end{array}$ & $\begin{array}{l}\text { Jul. } \rightarrow \text { Aug. } \\
4.52\end{array}$ & $\begin{array}{l}\text { Aug. } \rightarrow \text { Sep. } \\
-0.32\end{array}$ \\
\hline \multicolumn{7}{|c|}{ Year-on-year change relative to trend (percentage points) } \\
\hline Feb. 2020 & Mar. 2020 & $\begin{array}{l}\text { Apr. } \\
2020\end{array}$ & May 2020 & $\begin{array}{l}\text { Jul. } \\
2020\end{array}$ & Aug. 2020 & Sep. 2020 \\
\hline 1.47 & -13.44 & -12.00 & -7.05 & -6.49 & 2.94 & -6.25 \\
\hline
\end{tabular}

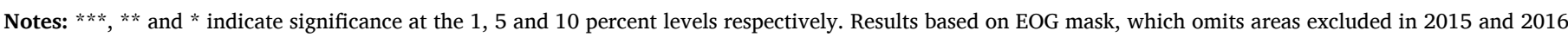

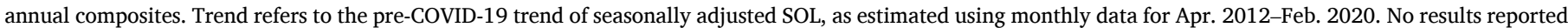
for June 2020 due to stray-light contamination of lights data.

(a)

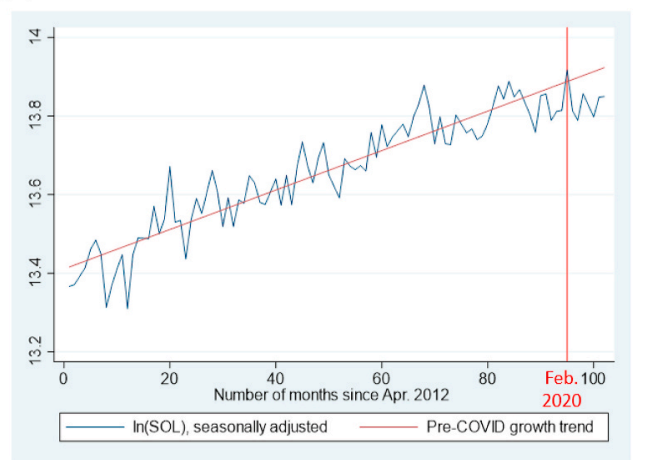

(b)

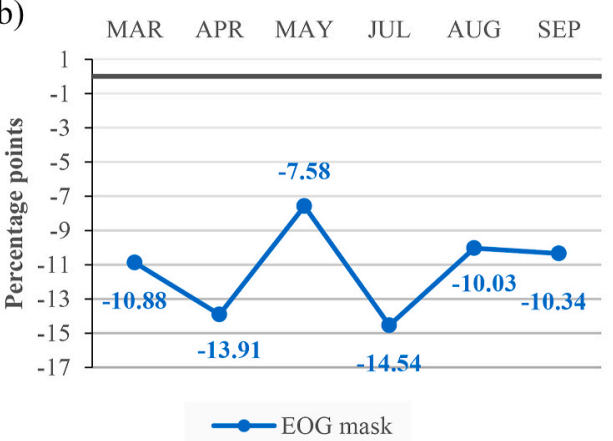

Notes: Results based on EOG mask, which omits areas excluded in 2015 and 2016 annual VIIRS composites. No results reported for June 2020 due to stray-light contamination of lights data.

Fig. 4. Changes in seasonally adjusted NTL intensity.

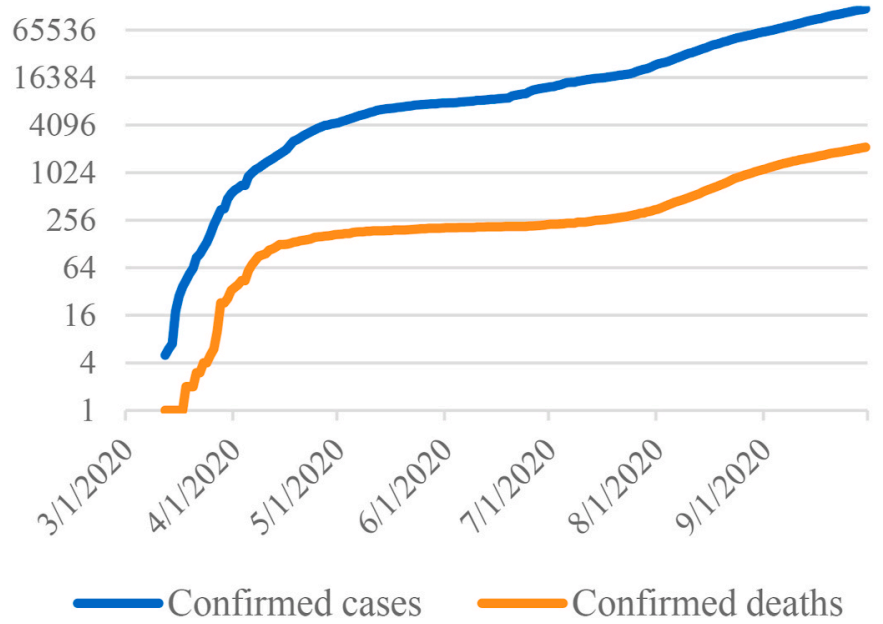

Fig. 5. Confirmed COVID-19 cases and deaths.

level. This coincided with an upturn in the growth in the number of confirmed COVID-19 cases (Fig. 5). In August, seasonally adjusted light intensity increased, but, by September, Morocco's seasonally adjusted light intensity remained, relative to the pre-crisis trend, 10.3 percentage points below its level in the final pre-COVID-19 month of February 2020. This is where it stood in March 2020 following the initial onset of the shock, implying the absence of any overall recovery with light intensity standing a statistically significant 7.3 percentage points below



Fig. 6. NPI stringency index.

the pre-crisis trend (Table 2).

One concern with the above findings, that we have already alluded to, is that they may be the spurious result of atmospheric effects that just happened to bias the measurement of lights downwards in March 2020 at the same time as the onset of COVID-19 in Morocco and the implementation of NPIs or, equivalently, the disappearance of a temporary upwards bias in the measurement of lights in February 2020 due to 
atmospheric effects. Some support for the latter possibility seems to be provided by Fig. 4(a), which shows that there was a large upward movement in the intensity of Morocco's lights between January and February 2020. Indeed, the magnitude of this upwards movement $(+9.8$ percentage points relative to the pre-COVID-19 trend) was almost as large as the subsequent downwards movement (- 10.9 percentage points) that occurred in March and coincided with the onset of COVID19. However, this would not explain the large year-on-year decline in the intensity of lights between March 2019 and March 2020. Also, the disappearance of a temporary February 2020 distortion cannot explain why light intensity would have remained significantly below its preCOVID-19 growth path for the remainder of the sample-period, which runs up until September 2020. Still, the noisiness of the seasonally adjusted SOL time series relative to the pre-COVID-19 growth path which is evident in Fig. 4(a) means that we cannot unequivocally ruleout the possibility that the results may be driven by unaccounted for (non-seasonal) atmospheric effects.

\subsection{Subnational results}

\subsubsection{Admin-1 regions ${ }^{35}$}

Table 3 and Fig. 7 present our subnational results which cover nine of Morocco's Admin-1 level regions, as defined by their current boundaries, which date back to $2015 .{ }^{36}$ The first finding to emphasize is that while all regions shared in March 2020's national lights decline, some suffered more than others. Thus, out of the nine regions analyzed, Fès Meknès experienced the largest month-on-month decline - 16.5 percentage points - in the intensity of its seasonally adjusted lights in March relative to its pre-COVID-19 trend growth path. Tanger - Tetouan - Al Hoceima and Oriental - RIF also experienced declines greater than 15 percentage points, while a further three (Rabat - Salé - Kénitra, DrâaTafilalet, and Marrakech - Safi) experienced declines more than 10 percentage points. The only region to escape a large fall in the intensity of its lights in March was Souss - Massa (- 0.5 percentage points). ${ }^{37}$ Given an assumed elasticity of 0.30 , a 15 (10) percentage point decline in light intensity is equivalent to a 4.5 (3.0) percentage point drop in real GDP, although, as noted above, any attempt to derive precise quantitative estimates of changes in real GDP needs to be treated with caution.

In addition to the heterogeneous movements of nighttime lights following the onset of Morocco's COVID-19 crisis in March 2020, Table 3 and Fig. 7 also reveal that the effects of the shock appear to have been highly persistent across regions. Thus, while light intensity levels relative to pre-crisis trends have fluctuated at the regional level since March, there is a strong correlation between the initial "impact" of the shock in March and the overall "impact" as observed in September 2020. This is reflected in an estimated correlation coefficient of 0.69 and an estimated Spearman's rank correlation coefficient of 0.75 between the

\footnotetext{
35 Again, we focus on results based on the EOG mask. Results are, however, similar regardless of the choice of mask.

${ }^{36}$ Our analysis excludes three sparsely populated regions that were not fully covered by the lights data provided by EOG under their subscription service. However, an analysis of December 2019 lights data, where we have complete coverage of all regions including these, shows that they accounted for only 4.6 percent of total SOL for that month (calculated using pixel values equal to or greater than one), which is consistent with their low overall density of economic activity. Furthermore, results from Gibson et al. (2021), based on data for Indonesia, China, and South Africa, suggest that VIIRS lights data are less of a reliable proxy for economic activity for low-density regions.

37 Similar to national level results, most Admin-1 regions experienced a month-on-month increase in light intensity in February 2020, just prior to the onset of COVID-19. Again, this raises some concern that the declines estimated for March 2020 may be the result of the disappearance of a temporary February 2020 distortion of lights that resulted in an upwards measurement bias. Although this seems unlikely to fully account for the results presented, we can, again, not unequivocally rule it out.
}

change in a region's seasonally adjusted light intensity between February and September and the change in its seasonally adjusted light intensity between February and March. Consistent with this, the two regions, Rabat - Salé - Kénitra and Tanger - Tetouan - Al Hoceima, that appear to have been initially hardest hit by the crisis remained the hardest hit in September. Conversely, Souss - Massa and Casablanca Settat, which were the two regions that appear to have been initially least hard hit, were also the only two to have recovered to levels of light intensity, relative to the pre-COVID-19 trend, that were above their precrisis levels in February (Fig. 7).

More generally, assuming that they are not driven by unaccounted for atmospheric distortions, our results allow us to distinguish between three groups of regions in Morocco - the hardest hit, the hard-hit and the recovered. In addition to Rabat - Salé - Kénitra and Tanger - Tetouan $\mathrm{Al}$ Hoceima, the hardest hit group also includes Fès - Meknès. Compared to their pre-crisis trends, these areas had September 2020 levels of light intensity between 19.2 and 26.0 percentage points lower than they were in February 2020. This corresponds to a 5.8-7.8 percentage points drop in real GDP given an elasticity of 0.30 with the caveat, again, that estimated real GDP changes need to be treated with caution. The hardhit group meanwhile comprises Drâa - Tafilalet, Marrakech - Safi, Oriental - RIF and Béni Mellal - Khénifra. This group suffered light intensity (estimated real GDP) declines between February and September 2020 in the range of 5.0-12.0 (1.5-3.6) percentage points. Finally, Souss - Massa and Casablanca - Settat are the recovered group, with September 2020 light intensity (estimated real GDP) levels that were 1.2 (0.4) and 5.7 (1.7) percentage points respectively above their February 2020 levels, relative to pre-crisis trends (Table 3, Fig. 7). However, whether Souss - Massa and Casablanca - Settat have retained their recovered status as Morocco's COVID-19 crisis has further evolved is an open question.

\subsubsection{Cities}

Table 4 reports results for the 14 Moroccan cities whose population exceeded 200,000 in 2015, where we define cities as "urban centers" following the European Commission's degree of urbanization methodology (Dijkstra and Poelman, 2014; Dijkstra et al., 2021). According to this definition, a city is composed of a contiguous set of $1 \mathrm{~km}^{2}$ pixels, each of which has a population density of at least 1500 people per $\mathrm{km}^{2}$ and whose collective population is at least $50,000 .{ }^{38}$ As might be expected, the results largely mirror those for Morocco's Admin-1 level regions. Thus, the cities that suffered the largest (smallest) declines in their seasonally adjusted nighttime lights in March 2020 relative to their pre-COVID-19 trends tended to be those which fall under the Admin-1 level regions whose seasonally adjusted lights also declined by the most (least) in March 2020. And, as at the Admin-1 level region, the "impacts" of the COVID-19 shock have been highly persistent across cities. This is again indicated by the high estimated correlation and Spearman's rank correlation coefficients ( 0.80 and 0.82 respectively) when comparing the change in seasonally adjusted lights between February and September 2020 with the corresponding change between February and March 2020 across cities. Indeed, these estimated correlation coefficients are even higher than the corresponding coefficients that we reported for the Admin-1 region level, indicating even stronger persistence at the city than at the regional level.

Notwithstanding the overall similarity of the results, however, we also observe some important differences in results across cities which belong to the same Admin-1 level region. This is the case, for example,

\footnotetext{
38 Population is measured using the European Commission's GHS-POP population grid, which is the same grid as that on which the population mask is based. The shapes of the 14 Moroccan cities were extracted from Urban Center Database UCDB R2019A (Florczyk et al., 2015). Results for cities were derived without applying a background noise mask given that background noise tends to be associated with non-urban areas.
} 
Table 3

Changes in light intensity relative to pre-COVID-19 trend (percentage points), Admin-1 regions.

\begin{tabular}{|c|c|c|c|c|c|c|}
\hline \multirow[t]{2}{*}{ Admin-1 unit } & \multicolumn{6}{|c|}{ Change from previous month, percentage points (Change from February 2020 , percentage points) } \\
\hline & $\begin{array}{l}\text { March } \\
2020\end{array}$ & $\begin{array}{l}\text { April } \\
2020\end{array}$ & $\begin{array}{l}\text { May } \\
2020\end{array}$ & $\begin{array}{l}\text { July } \\
2020\end{array}$ & $\begin{array}{l}\text { August } \\
2020\end{array}$ & $\begin{array}{l}\text { Sept. } \\
2020\end{array}$ \\
\hline Rabat - Salé - Kénitra & $\begin{array}{l}-11.95 \\
(-11.95)\end{array}$ & $\begin{array}{l}-3.11 \\
(-15.06)\end{array}$ & $\begin{array}{l}3.58 \\
(-11.48)\end{array}$ & $\begin{array}{l}-15.60 \\
(-27.08)\end{array}$ & $\begin{array}{l}11.23 \\
(-15.85)\end{array}$ & $\begin{array}{l}-10.14 \\
(-25.99)\end{array}$ \\
\hline Tanger - Tetouan - Al Hoceima & $\begin{array}{l}-15.33 \\
(-15.33)\end{array}$ & $\begin{array}{l}-3.76 \\
(-19.10)\end{array}$ & $\begin{array}{l}7.13 \\
(-11.96)\end{array}$ & $\begin{array}{l}-6.98 \\
(-18.95)\end{array}$ & $\begin{array}{l}3.40 \\
(-15.55)\end{array}$ & $\begin{array}{l}-6.52 \\
(-22.07)\end{array}$ \\
\hline Fès - Meknès & $\begin{array}{l}-16.49 \\
(-16.49)\end{array}$ & $\begin{array}{l}-11.79 \\
(-28.28)\end{array}$ & $\begin{array}{l}13.47 \\
(-14.82)\end{array}$ & $\begin{array}{l}-4.47 \\
(-19.28)\end{array}$ & $\begin{array}{l}1.36 \\
(-17.93)\end{array}$ & $\begin{array}{l}-1.27 \\
(-19.20)\end{array}$ \\
\hline Béni Mellal - Khénifra & $\begin{array}{l}-7.42 \\
(-7.42)\end{array}$ & $\begin{array}{l}-9.97 \\
(-17.39)\end{array}$ & $\begin{array}{l}8.37 \\
(-9.02)\end{array}$ & $\begin{array}{l}-2.28 \\
(-11.29)\end{array}$ & $\begin{array}{l}0.90 \\
(-10.39)\end{array}$ & $\begin{array}{l}-1.57 \\
(-11.96)\end{array}$ \\
\hline Oriental - RIF & $\begin{array}{l}-15.28 \\
(-15.28)\end{array}$ & $\begin{array}{l}-2.65 \\
(-17.94)\end{array}$ & $\begin{array}{l}12.41 \\
(-5.53)\end{array}$ & $\begin{array}{l}-7.82 \\
(-13.35)\end{array}$ & $\begin{array}{l}3.78 \\
(-9.57)\end{array}$ & $\begin{array}{l}3.18 \\
(-6.39)\end{array}$ \\
\hline Marrakech - Safi & $\begin{array}{l}-11.62 \\
(-11.62)\end{array}$ & $\begin{array}{l}-6.92 \\
(-18.54)\end{array}$ & $\begin{array}{l}11.76 \\
(-6.78)\end{array}$ & $\begin{array}{l}-4.08 \\
(-10.86)\end{array}$ & $\begin{array}{l}3.16 \\
(-7.70)\end{array}$ & $\begin{array}{l}1.69 \\
(-6.01)\end{array}$ \\
\hline Drâa - Tafilalet & $\begin{array}{l}-11.65 \\
(-11.65)\end{array}$ & $\begin{array}{l}7.26 \\
(-4.40)\end{array}$ & $\begin{array}{l}1.20 \\
(-3.19)\end{array}$ & $\begin{array}{l}-6.10 \\
(-9.29)\end{array}$ & $\begin{array}{l}-0.87 \\
(-10.16)\end{array}$ & $\begin{array}{l}5.21 \\
(-4.95)\end{array}$ \\
\hline Casablanca - Settat & $\begin{array}{l}-6.49 \\
(-6.49)\end{array}$ & $\begin{array}{l}4.90 \\
(-1.58)\end{array}$ & $\begin{array}{l}-3.72 \\
(-5.30)\end{array}$ & $\begin{array}{l}-4.78 \\
(-10.08)\end{array}$ & $\begin{array}{l}8.59 \\
(-1.49)\end{array}$ & $\begin{array}{l}2.67 \\
(1.18)\end{array}$ \\
\hline Souss - Massa & $\begin{array}{l}-0.53 \\
(-0.53)\end{array}$ & $\begin{array}{l}-7.88 \\
(-8.31)\end{array}$ & $\begin{array}{l}13.66 \\
(5.35)\end{array}$ & $\begin{array}{l}-8.18 \\
(-2.83)\end{array}$ & $\begin{array}{l}-4.23 \\
(-7.06)\end{array}$ & $\begin{array}{l}12.75 \\
(5.70)\end{array}$ \\
\hline Mean & $\begin{array}{l}-10.75 \\
(-10.75)\end{array}$ & $\begin{array}{l}-3.77 \\
(-14.51)\end{array}$ & $\begin{array}{l}7.54 \\
(-6.97)\end{array}$ & $\begin{array}{l}-6.70 \\
(-13.67)\end{array}$ & $\begin{array}{l}3.04 \\
(-10.63)\end{array}$ & $\begin{array}{l}0.67 \\
(-9.97)\end{array}$ \\
\hline Median & $\begin{array}{l}-11.65 \\
(-11.65)\end{array}$ & $\begin{array}{l}-3.76 \\
(-17.39)\end{array}$ & $\begin{array}{l}8.37 \\
(-6.78)\end{array}$ & $\begin{array}{l}-6.10 \\
(-11.29)\end{array}$ & $\begin{array}{l}3.16 \\
(-10.16)\end{array}$ & $\begin{array}{l}1.69 \\
(-6.39)\end{array}$ \\
\hline
\end{tabular}

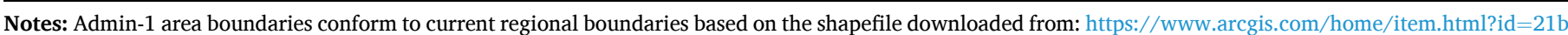
cbcaa915c433ba7c7850bafeede7b. No results reported for June 2020 due to stray-light contamination of the lights data.

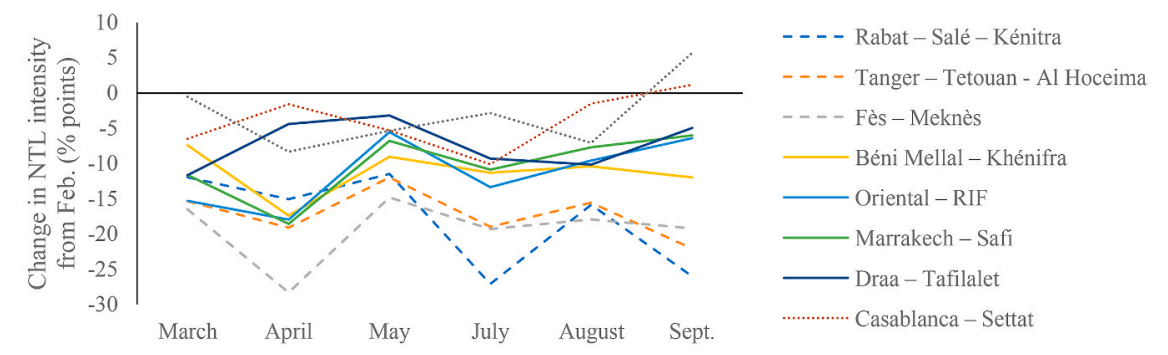

Notes: Admin-1 area boundaries conform to current regional boundaries based on the shapefile downloaded from: https://www.arcgis.com/home/item.html?id=21bcbcaa915c433ba7c7850bafeede $7 \mathrm{~b}$. No results reported for June 2020 due to stray-light contamination of the lights data.

Fig. 7. Changes in light intensity relative to pre-COVID-19 trend (percentage points), Admin-1 areas.

for the cities of Tangier and Tetouan, both of which are in the region of Tanger - Tetouan - Al Hoceima. Hence, the decline in seasonally adjusted light intensity, relative to the pre-COVID-19 trend, that Tangier suffered between February and March 2020 was 23.8 percentage points, which was nearly double the 12 percentage points decline that Tetouan suffered. Furthermore, by September 2020, Tangier's decline in light intensity from February 2020 had further increased to 37.3 percentage points, while Tetouan's decline remained roughly the same as in March 2020 at 13.7 percentage points.

Comparing Table 4 with Tables 2 and 3, we can further see that the declines in seasonally adjusted lights, relative to pre-COVID-19 trends, are frequently larger at the city level than either at the Admin-1 region or national levels. This suggests that the negative economic "impacts" of the COVID-19 crisis in Morocco have been most heavily felt in cities subject again to the same, previously expressed caveat, that we cannot entirely rule-out the possibility that our results are driven by unaccounted for (non-seasonal) atmospheric effects that distort the measurement of lights. It also suggests that our results at the national and Admin-1 region levels are not driven by the dimming of lights along, for example, the transport routes that connect cities. This conclusion is corroborated by the fact that the results that we obtain at both the national and Admin-1 region levels are qualitatively similar when, instead of the EOG mask, we use the built-up area mask, which, as Fig. 1(d) shows, masks out roads between cities. In the case of China, Liu et al. (2020) report that the dimming of lights associated with the pandemic mainly occurred in the commercial centers of cities. Although further work matching nighttime lights data with land use maps would be required to establish this, it seems plausible that a similar story may hold for Morocco.

\section{Conclusion}

This paper has explored the potential for high frequency nighttime lights data to provide "near real-time" tracking of the economic impacts of the COVID-19 crisis for the specific case of Morocco. At the national level, there exists a strong correlation between quarterly movements in Morocco's overall light intensity and movements in its real GDP, which supports the use of lights to track the economic impacts of the COVID-19 crisis at both higher temporal frequencies and at the subnational level, for which GDP data are unavailable. Consistent with large economic impacts of the crisis, Morocco experienced a large drop, relative to the pre-COVID-19 crisis trend, in the overall intensity of its lights in March 2020 , from which it has subsequently struggled to recover. At the subnational level, while all regions shared in March's national decline in nighttime light intensity, Rabat - Salé - Kénitra, Tanger - Tetouan - Al Hoceima, and Fès - Meknès experienced much larger declines than 
Table 4

Changes in light intensity relative to pre-COVID-19 trend (percentage points), cities with 2015 population $>200,000$.

\begin{tabular}{|c|c|c|c|c|c|c|c|}
\hline \multirow[b]{2}{*}{ City } & \multirow[b]{2}{*}{ Admin-1 unit } & \multicolumn{6}{|c|}{ Change from previous month, percentage points (Change from February 2020, percentage points) } \\
\hline & & $\begin{array}{l}\text { March } \\
2020\end{array}$ & $\begin{array}{l}\text { April } \\
2020\end{array}$ & $\begin{array}{l}\text { May } \\
2020\end{array}$ & $\begin{array}{l}\text { July } \\
2020\end{array}$ & $\begin{array}{l}\text { August } \\
2020\end{array}$ & $\begin{array}{l}\text { Sept. } \\
2020\end{array}$ \\
\hline Tangier & Tanger - Tetouan - Al Hoceima & $\begin{array}{l}-23.76 \\
(-23.76)\end{array}$ & $\begin{array}{l}-6.53 \\
(-30.29)\end{array}$ & $\begin{array}{l}10.33 \\
(-19.96)\end{array}$ & $\begin{array}{l}-2.86 \\
(-22.82)\end{array}$ & $\begin{array}{l}-3.32 \\
(-26.14)\end{array}$ & $\begin{array}{l}-11.18 \\
(-37.32)\end{array}$ \\
\hline Rabat & Rabat - Salé - Kénitra & $\begin{array}{l}-12.27 \\
(-12.27)\end{array}$ & $\begin{array}{l}-2.93 \\
(-15.20)\end{array}$ & $\begin{array}{l}2.04 \\
(-13.16)\end{array}$ & $\begin{array}{l}-21.30 \\
(-34.46)\end{array}$ & $\begin{array}{l}16.88 \\
(-17.58)\end{array}$ & $\begin{array}{l}-14.07 \\
(-31.65)\end{array}$ \\
\hline Fez & Fès - Meknès & $\begin{array}{l}-23.23 \\
(-23.23)\end{array}$ & $\begin{array}{l}-14.94 \\
(-38.16)\end{array}$ & $\begin{array}{l}10.31 \\
(-27.85)\end{array}$ & $\begin{array}{l}-4.14 \\
(-31.99)\end{array}$ & $\begin{array}{l}4.68 \\
(-27.31)\end{array}$ & $\begin{array}{l}-0.52 \\
(-27.83)\end{array}$ \\
\hline Meknes & Fès - Meknès & $\begin{array}{l}-17.67 \\
(-17.67)\end{array}$ & $\begin{array}{l}-13.27 \\
(-30.93)\end{array}$ & $\begin{array}{l}9.54 \\
(-21.39)\end{array}$ & $\begin{array}{l}2.20 \\
(-19.18)\end{array}$ & $\begin{array}{l}-0.45 \\
(-19.63)\end{array}$ & $\begin{array}{l}-6.84 \\
(-26.48)\end{array}$ \\
\hline Kénitra & Rabat - Salé - Kénitra & $\begin{array}{l}-17.64 \\
(-17.64)\end{array}$ & $\begin{array}{l}1.87 \\
(-15.77)\end{array}$ & $\begin{array}{l}4.82 \\
(-10.95)\end{array}$ & $\begin{array}{l}-15.27 \\
(-26.22)\end{array}$ & $\begin{array}{l}16.27 \\
(-9.95)\end{array}$ & $\begin{array}{l}-11.70 \\
(-21.64)\end{array}$ \\
\hline Khouribga & Béni Mellal - Khénifra & $\begin{array}{l}-14.87 \\
(-14.87)\end{array}$ & $\begin{array}{l}-4.21 \\
(-19.08)\end{array}$ & $\begin{array}{l}7.92 \\
(-11.16)\end{array}$ & $\begin{array}{l}2.61 \\
(-8.56)\end{array}$ & $\begin{array}{l}3.01 \\
(-5.55)\end{array}$ & $\begin{array}{l}-11.03 \\
(-16.58)\end{array}$ \\
\hline Marrakesh & Marrakech - Safi & $\begin{array}{l}-12.45 \\
(-12.45)\end{array}$ & $\begin{array}{l}-17.05 \\
(-29.50)\end{array}$ & $\begin{array}{l}12.92 \\
(-16.58)\end{array}$ & $\begin{array}{l}-6.76 \\
(-23.33)\end{array}$ & $\begin{array}{l}3.81 \\
(-19.52)\end{array}$ & $\begin{array}{l}2.95 \\
(-16.57)\end{array}$ \\
\hline Tetouan & Tanger - Tetouan - Al Hoceima & $\begin{array}{l}-12.03 \\
(-12.03)\end{array}$ & $\begin{array}{l}-5.91 \\
(-17.94)\end{array}$ & $\begin{array}{l}-2.33 \\
(-20.27)\end{array}$ & $\begin{array}{l}-10.36 \\
(-30.63)\end{array}$ & $\begin{array}{l}28.39 \\
(-2.24)\end{array}$ & $\begin{array}{l}-11.46 \\
(-13.70)\end{array}$ \\
\hline Oujda & Oriental - RIF & $\begin{array}{l}-15.82 \\
(-15.82)\end{array}$ & $\begin{array}{l}-22.43 \\
(-38.24)\end{array}$ & $\begin{array}{l}31.14 \\
(-7.10)\end{array}$ & $\begin{array}{l}1.85 \\
(-5.25)\end{array}$ & $\begin{array}{l}-7.12 \\
(-12.38)\end{array}$ & $\begin{array}{l}6.72 \\
(-5.65)\end{array}$ \\
\hline El Jadida & Casablanca - Settat & $\begin{array}{l}-13.51 \\
(-13.51)\end{array}$ & $\begin{array}{l}3.15 \\
(-10.36)\end{array}$ & $\begin{array}{l}-4.31 \\
(-14.67)\end{array}$ & $\begin{array}{l}3.36 \\
(-11.30)\end{array}$ & $\begin{array}{l}3.59 \\
(-7.71)\end{array}$ & $\begin{array}{l}7.14 \\
(-0.57)\end{array}$ \\
\hline Nador & Oriental - RIF & $\begin{array}{l}-10.47 \\
(-10.47)\end{array}$ & $\begin{array}{l}-4.50 \\
(-14.97)\end{array}$ & $\begin{array}{l}0.59 \\
(-14.39)\end{array}$ & $\begin{array}{l}4.44 \\
(-9.94)\end{array}$ & $\begin{array}{l}6.57 \\
(-3.38)\end{array}$ & $\begin{array}{l}4.81 \\
(1.43)\end{array}$ \\
\hline Casablanca & Casablanca - Settat & $\begin{array}{l}-9.70 \\
(-9.70)\end{array}$ & $\begin{array}{l}11.08 \\
(1.38)\end{array}$ & $\begin{array}{l}-4.62 \\
(-3.24)\end{array}$ & $\begin{array}{l}-9.39 \\
(-12.63)\end{array}$ & $\begin{array}{l}10.65 \\
(-1.98)\end{array}$ & $\begin{array}{l}3.62 \\
(1.64)\end{array}$ \\
\hline Safi & Marrakech - Safi & $\begin{array}{l}-7.72 \\
(-7.72)\end{array}$ & $\begin{array}{l}-7.15 \\
(-14.86)\end{array}$ & $\begin{array}{l}4.21 \\
(-10.66)\end{array}$ & $\begin{array}{l}12.75 \\
(2.10)\end{array}$ & $\begin{array}{l}2.81 \\
(4.91)\end{array}$ & $\begin{array}{l}-2.45 \\
(2.46)\end{array}$ \\
\hline Agadir & Souss - Massa & $\begin{array}{l}-1.27 \\
(-1.27)\end{array}$ & $\begin{array}{l}-3.59 \\
(-4.86)\end{array}$ & $\begin{array}{l}10.21 \\
(5.35)\end{array}$ & $\begin{array}{l}-8.50 \\
(-3.15)\end{array}$ & $\begin{array}{l}-5.02 \\
(-8.17)\end{array}$ & $\begin{array}{l}17.31 \\
(9.14)\end{array}$ \\
\hline Mean & & $\begin{array}{c}-13.74 \\
(-13.74)\end{array}$ & $\begin{array}{l}-6.17 \\
(-19.91)\end{array}$ & $\begin{array}{l}6.63 \\
(-13.29)\end{array}$ & $\begin{array}{l}-3.67 \\
(-16.96)\end{array}$ & $\begin{array}{l}5.77 \\
(-11.19)\end{array}$ & $\begin{array}{l}-1.91 \\
(-13.10)\end{array}$ \\
\hline Median & & $\begin{array}{l}-12.98 \\
(-12.98)\end{array}$ & $\begin{array}{l}-5.20 \\
(-16.86)\end{array}$ & $\begin{array}{l}6.37 \\
(-13.77)\end{array}$ & $\begin{array}{l}-3.50 \\
(-15.91)\end{array}$ & $\begin{array}{l}3.70 \\
(-9.06)\end{array}$ & $\begin{array}{l}-1.49 \\
(-15.13)\end{array}$ \\
\hline
\end{tabular}

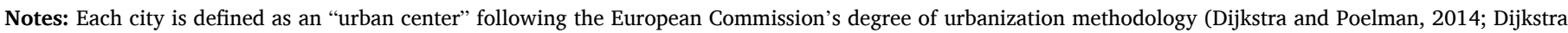
et al., 2021). Table is restricted to urban centers with a population of more than 200,000 in 2015.

others. Since then, the relative effects of the COVID-19 shock across regions appear to have largely persisted. Similar, and, indeed, stronger, persistence is also evident for our sample of Moroccan cities. Moreover, the effects of the COVID-19 crisis on lights appear to have been, in many cases, stronger at the city than either at the subnational regional or national levels, which is consistent with cities bearing much of the brunt of the crisis.

Our analysis can potentially be extended in several directions. Thus, while we have analyzed the evolution of nighttime lights, as a proxy measure of economic activity, at both the national and sub-national (regional and city) levels for Morocco, the methods showcased in this paper can equally be applied to other Middle East and North African (MENA) countries, taking advantage of the region's low cloud-cover which facilitates frequent high-quality observation of lights. A second natural extension would be to investigate the underlying determinants of the heterogenous nighttime lights reactions of Morocco's different regions and cities to the COVID-19 crisis, which might include, for example, differences in their economic and demographic structures, as well as differences in the spread of the disease itself and the associated policy reactions. A final potential extension would be to analyze the evolution of lights in response to the crisis within Morocco's cities in the spirit of Liu et al.'s work for China to see if the negative impacts of the COVID-19 crisis are associated with particular geographic areas - e.g., commercial centers - within cities.

Finally, there are several crucial caveats that should be kept in mind when considering the results in this paper. First, while we have demonstrated that quarterly changes in nighttime light intensity are significantly correlated with quarterly movements in real GDP for Morocco, we have also found that this relationship contains significant noise and that the timing of changes in direction in light intensity are only imperfectly aligned with the timing of changes in the direction of real GDP. Second, at both the national and sub-national levels, we have shown that the large decline in nighttime light intensity that occurred in March 2020 at the onset of the COVID-19 crisis in Morocco was preceded by an almost equally large increase in light intensity in February 2020. This raises the concern that our results may be driven by temporary measurement error driven by unaccounted for atmospheric distortions that might have biased upwards the measurement of light intensity in February. While the fact that there were also year-on-year declines in light intensity between March 2019 and March 2020 provides some reassurance, further research is required to definitively establish that the estimated changes in light intensity reported are driven by anthropogenic causes. Third, and finally, we have seen that Morocco is particularly affected by the distortion of its June lights data due to the straylight phenomenon, which led to us dropping data for this month. Taken together, these caveats imply that the results presented in this paper should be taken as suggestive of the evolution of economic activity following the onset of the COVID-19 crisis rather than as providing the final word on the magnitude of this evolution, where much more caution is needed. Ideally, one would like to triangulate the results presented in this paper with those obtained from other high frequency, potentially near real-time, proxy measures of economic activity for which the possible measurement errors are orthogonal to those in the lights data.

\section{Declaration of competing interest}

The authors declare that they have no known competing financial interests or personal relationships that could have appeared to influence the work reported in this paper. 


\section{Acknowledgments}

The author thanks Hogeun Park and New Light Technologies - and especially Ran Goldblatt - for their processing of the nighttime lights data. He also thanks Jesko Hentschel, Carole Megevand, Jaafar Sadok Friaa, Larbi Jaïdi, Mounssif Aderkaoui, Amjad Khan, Augustin Maria, Chaymae Belouali, Somik Lall, Robert Beyer, Amina Coulibaly and three anonymous referees for their helpful comments on an earlier draft of this paper. The findings, interpretations, and conclusions expressed in this paper are entirely those of the author. They do not necessarily represent the views of the International Bank for Reconstruction and Development/World Bank and its affiliated organizations, or those of the Executive Directors of the World Bank or the governments they represent.

\section{Annex 1. Relationship between nighttime light intensity and sectoral GDP}

\section{Table A1}

Relationship between nighttime lights and GDP generated by different sectors, quarterly data (2012 Q3 - 2020 Q1).

\begin{tabular}{|c|c|c|c|c|c|c|}
\hline & Time trend & Time trend + quarter effects & Year effects & Year + quarter effects & De-trended (time trend) & De-trended (year effects) \\
\hline & [1a] & [1b] & [2a] & {$[2 \mathrm{~b}]$} & [3a] & {$[3 \mathrm{~b}]$} \\
\hline \multicolumn{7}{|c|}{ EOG mask } \\
\hline \multicolumn{7}{|l|}{ Industry } \\
\hline $\ln (\mathrm{SOL})$ & $\begin{array}{l}0.143 \\
(1.49)\end{array}$ & $\begin{array}{l}0.051 \\
(0.90)\end{array}$ & $\begin{array}{l}0.453^{* * * *} \\
(3.91)\end{array}$ & $\begin{array}{l}0.173^{* *} \\
(2.58)\end{array}$ & $\begin{array}{l}0.143 \\
(1.52)\end{array}$ & $\begin{array}{l}0.453^{* * * *} \\
(4.28)\end{array}$ \\
\hline $\mathrm{R}^{2}$ & 0.86 & 0.95 & 0.90 & 0.98 & 0.07 & 0.49 \\
\hline \multicolumn{7}{|l|}{ Services } \\
\hline $\ln (\mathrm{SOL})$ & $\begin{array}{l}-0.057 \\
(-1.07)\end{array}$ & $\begin{array}{l}-0.078^{*} \\
(-2.05)\end{array}$ & $\begin{array}{l}0.141^{* * *} \\
(3.02)\end{array}$ & $\begin{array}{l}-0.015 \\
(-0.52)\end{array}$ & $\begin{array}{l}-0.057 \\
(-1.11)\end{array}$ & $\begin{array}{l}0.141^{* * * *} \\
(3.78)\end{array}$ \\
\hline $\mathrm{R}^{2}$ & 0.97 & 0.98 & 0.97 & 0.99 & 0.05 & 0.23 \\
\hline \multicolumn{7}{|c|}{ Agriculture } \\
\hline $\ln (\mathrm{SOL})$ & $\begin{array}{l}0.460^{* *} \\
(2.11)\end{array}$ & $\begin{array}{l}0.533^{* *} \\
(2.81)\end{array}$ & $\begin{array}{l}0.026 \\
(0.21)\end{array}$ & $\begin{array}{l}0.159 \\
(0.96)\end{array}$ & $\begin{array}{l}0.460^{* * *} \\
(2.15)\end{array}$ & $\begin{array}{l}0.026 \\
(0.26)\end{array}$ \\
\hline $\mathrm{R}^{2}$ & 0.43 & 0.48 & 0.92 & 0.93 & 0.12 & 0.00 \\
\hline \multicolumn{7}{|c|}{ Cluster mask } \\
\hline \multicolumn{7}{|l|}{ Industry } \\
\hline $\ln (\mathrm{SOL})$ & $\begin{array}{l}0.143^{*} \\
(1.77)\end{array}$ & $\begin{array}{l}0.063 \\
(1.11)\end{array}$ & $\begin{array}{l}0.413^{* * *} \\
(3.58)\end{array}$ & $\begin{array}{l}0.149 * \\
(2.00)\end{array}$ & $\begin{array}{l}0.143^{*} \\
(1.82)\end{array}$ & $\begin{array}{l}0.413^{* * * *} \\
(4.48)\end{array}$ \\
\hline $\mathrm{R}^{2}$ & 0.86 & 0.95 & 0.90 & 0.97 & 0.10 & 0.48 \\
\hline \multicolumn{7}{|l|}{ Services } \\
\hline $\ln (\mathrm{SOL})$ & $\begin{array}{l}-0.013 \\
(-0.39)\end{array}$ & $\begin{array}{l}-0.03 \\
(-1.04)\end{array}$ & $\begin{array}{l}0.137^{* * *} \\
(3.63)\end{array}$ & $\begin{array}{l}-0.002 \\
(-0.06)\end{array}$ & $\begin{array}{l}-0.013 \\
(-0.40)\end{array}$ & $\begin{array}{l}0.137^{* * * *} \\
(4.55)\end{array}$ \\
\hline $\mathrm{R}^{2}$ & 0.97 & 0.98 & 0.97 & 0.99 & 0.00 & 0.252 \\
\hline \multicolumn{7}{|c|}{ Agriculture } \\
\hline $\ln (\mathrm{SOL})$ & $\begin{array}{l}0.335^{*} \\
(1.72)\end{array}$ & $\begin{array}{l}0.398^{* *} \\
(2.18)\end{array}$ & $\begin{array}{l}-0.052 \\
(-0.40)\end{array}$ & $\begin{array}{l}0.032 \\
(0.19)\end{array}$ & $\begin{array}{l}0.335^{*} \\
(1.77)\end{array}$ & $\begin{array}{l}-0.05 \\
(-0.50)\end{array}$ \\
\hline $\mathrm{R}^{2}$ & 0.40 & 0.46 & 0.92 & 0.93 & 0.09 & 0.01 \\
\hline
\end{tabular}

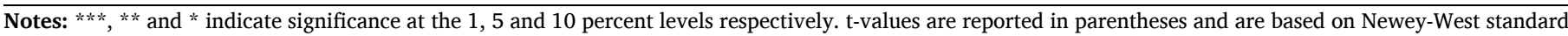
errors, assuming a first-order serial correlation process. Estimated constant terms in the regressions not reported.

Annex 2. Full results from estimation of equation (4) - EOG mask

Table A2

Full results from estimation of equation (4).

\begin{tabular}{ll}
\hline Dependent variable: $\ln \left(S O L_{i, m}\right)$ & \\
\hline & EOG mask \\
\hline Time trend & $0.005^{* * *}$ \\
& $(16.02)$ \\
COVID $\times$ & \\
March & $-0.079^{* *}$ \\
& $(-2.52)$ \\
April & $-0.109^{* * *}$ \\
& $(-4.75)$ \\
May & $-0.046^{* *}$ \\
& $(-2.48)$ \\
July & $-0.115^{* * *}$ \\
& $(-4.10)$ \\
August & $-0.070^{* *}$ \\
& $(-2.49)$ \\
Sept. & $-0.073^{* * *}$ \\
& $(-3.06)$
\end{tabular}


Table A2 (continued)

\begin{tabular}{ll}
\hline Dependent variable: $\ln \left(S O L_{i, m}\right)$ \\
\hline Constant & EOG mask \\
\hline$R^{2}$ & $\begin{array}{l}13.411^{* * *} \\
(578.63)\end{array}$ \\
$F$ & 0.868 \\
$n$ & $7.73^{* * *}$ \\
\hline
\end{tabular}

Notes: $* * * * *$ and $*$ indicate significance at the 1,5 and 10 percent levels respectively. $t$ values are reported in parentheses and are based on Newey-West standard errors, assuming a first-order serial correlation process. $F(12,75)$ refers to an F-test of the joint significance of all explanatory variables with 12 and 75 degrees of freedom. Regressions also include month dummies (estimated coefficients not reported) but exclude June data due to stray-light contamination of the data. EOG mask excludes areas excluded in 2015 and 2016 annual VIIRS composites.

\section{References}

Beyer, R.C.M., Franco-Bedoya, S., Galdo, V., 2021. Examining the Economic Impact of COVID-19 in India through Daily Electricity Consumption and Nighttime Light Intensity, vol. 140. World Development (April).

Bleakley, H., Lin, J., 2012. Portage and path dependence. Q. J. Econ. 127 (2), 587-644.

Chen, X., Nordhaus, W., 2011. Using luminosity data as a proxy for economic statistics. Proc. Natl. Acad. Sci. Unit. States Am. 108 (21), 8589-8594.

Chetty, R., Friedman, J., Hendren, N., Stepner, M., The Opportunity Insights Team, 2020. The Economic Impacts of COVID-19: Evidence from a New Public Database Built Using Private Sector Data. NBER Working Paper No. 27431, Boston, M.A.

Chodorow-Reich, G., Gopinath, G., Mishra, P., Naraynan, A., 2020. Cash and the economy: evidence from India's demonetization. Q. J. Econ. 135 (1), 57-103.

Elvidge, C.D., Baugh, K., Zhizhin, M., Hsu, F.-C., Ghosh, T., 2017. VIIRS night-time lights Int. J. Rem. Sens. 38 (1), 5860-5879.

Elvidge, C.D., Ghosh, T., Hsu, F.-C., Zhizhin, M., Bazilian, M., 2020. The dimming of lights in China during the COVID-19 pandemic. Rem. Sens. 12 (17).

Findley, D.F., Monsell, B.C., Bell, W.R., Otto, M.C., Chen, B.-C., 1998. New capabilities and methods of the X-12-ARIMA seasonal-adjustment program. J. Bus. Econ. Stat. 16 (2), 127-152.

Florczyk, A., Corbane, C., Schiavina, M., Pesaresi, M., Maffenini, L., Melchiorri, M., Politis, P., Sabo, F., Freire, S., Ehrlich, D., Kemper, T., Tommasi, P., Airaghi, D., Zanchetta, L., 2019. GHS Urban Centre Database 2015, Multitemporal and Multidimensional Attributes, R2019A. European Commission, Joint Research Centre (JRC). https://data.jrc.ec.europa.eu/dataset/53473144-b88c-44bc-b4a3-458 3ed1f547e.

Gibson, J., 2020. Better night lights data, for longer. Oxf. Bull. Econ. Stat. https://doi. org/10.1111/obes.12417.

Gibson, J., Olivia, S., Boe-Gibson, G., 2020. Night lights in economics: sources and uses. J. Econ. Surv. 34 (5), 955-980.

Gibson, J., Olivia, S., Boe-Gibson, G., Li, C., 2021. Which night lights data should we use in economics, and where? J. Dev. Econ. https://doi.org/10.1016/j. jdeveco. 2020.102602.

Goldblatt, R., Heilmann, K., Vaizman, Y., 2020. Can medium-resolution satellite imagery measure economic activity at small geographies? Evidence from lansat in Vietnam. World Bank Econ. Rev. 34 (3), 635-653.

Hale, T., Angrist, N., Cameron-Blake, E., Hallas, L., Kira, B., Majumdar, S., Petherick, A., Phillips, T., Tatlow, H., Webster, S., 2020. Oxford COVID-19 Government Response Tracker. Blavatnik School of Government, University of Oxford, Oxford.
Henderson, J.V., Storeygard, A., Weil, D.N., 2012. Measuring economic growth from outer space. Am. Econ. Rev. 102 (2), 994-1028.

IMF, 2020a. World Economic Outlook: A Long and Difficult Ascent. October 2020. International Monetary Fund, Washington, D.C.

IMF, 2020b. World Economic Outlook: Tentative Stabilization, Sluggish Recovery? January 2020. International Monetary Fund, Washington, D.C

Jedwab, R., Pereira, D., Roberts, M., 2021. Cities of workers, children or seniors? Stylized facts and possible implications for growth in a global sample of cities. Reg. Sci. Urban Econ. https://doi.org/10.1016/j.regsciurbeco.2020.103610.

Liu, Q., Sha, D., Liu, W., Houser, P., Zhang, L., Hou, R., Lan, H., Flynn, C., Lu, M., Hu, T., Yang, C., 2020. Spatiotemporal patterns of COVID-19 impact on human activities and environment in mainland China using nighttime light and air quality data. Rem. Sens. 12 (10), 1576.

Masaki, T., Nakamura, S., Newhouse, D., 2020. How Is the COVID-19 Crisis Affecting Nitrogen Dioxide Emissions in Sub-saharan Africa? World Bank Poverty \& Equity Note Number 21 The World Bank, Washington, D.C.

Newey, W.K., West, K.D., 1987. A simple, positive semi-definite heteroskedasticity and autocorrelation consistent covariance matrix. Econometrica 55 (3), 703-708.

Roberts, M. (forthcoming). "Shining a light on urban and spatial development" in IjjaszVasquez, E.J. and A. Jha (eds.), Disruptive Technologies in Sustainable Development. Washington, D.C.: The World Bank.

Roberts, M., 2018. The many dimensions of urbanization and the productivity of cities in Latin America and the caribbean. In: Ferreyra, M.M., Roberts, M. (Eds.), Raising the Bar for Productive Cities in Latin America and the Caribbean. The World Bank, Washington, D.C.

Small, C., 2019. Multisensor characterization of urban morphology and network structure. Rem. Sens. 11 (18), 2162.

Storeygard, A., 2016. Farther on down the road: transport costs, trade and urban growth. Rev. Econ. Stud. 83 (3), 1263-1295.

Sutton, P.C., Elvidge, C.D., Ghosh, T., 2007. Estimation of gross domestic product at subnational scales using nighttime satellite imagery. Int. J. Ecol. Econ. Stat. 8 (S07), 5-21.

Woloszko, N., 2020. A Weekly Tracker of Activity Based on Machine Learning and Google Trends. OECD Publishing, Paris. OECD Economics Department Working Papers 1634.

World Bank, 2020. Open Nightlights Tutorial. https://worldbank.github.io/OpenNight Lights/welcome.html.

World Bank, 2021. Global Economic Prospects: January 2021. The World Bank, Washington, D.C. 